\title{
Short communication: Characterization of Shiga toxin-producing Escherichia coli isolated from newborn, milk-fed, and growing calves in Argentina
}

\author{
D. Fernández, ${ }^{1}$ M. E. Sanz, A. E. Parma, and N. L. Padola \\ Laboratorio de Inmunoquímica y Biotecnología, Centro de Investigaciones Veterinarias Tandil-Consejo Nacional de Investigaciones Científicas \\ y Técnicas-Comisión de Investigaciones Cientificas de la Provincia de Buenos Aires (CIVETAN-CONICET-CICPBA), Facultad Ciencias \\ Veterinarias, Universidad Nacional del Centro de la Provincia de Buenos Aires, Paraje Arroyo Seco s/n (7000) Tandil, Argentina
}

\begin{abstract}
Shiga toxin-producing Escherichia coli (STEC) cause foodborne pathogenic disease that is shed in the feces of cattle. The aim of this study was to evaluate how early young calves are colonized by STEC strains, potentially pathogenic for humans, and the prevalence in different calf categories. From 808 rectal swabs analyzed by PCR, $38 \%$ were stx positive. The prevalence in newborn ( $<24 \mathrm{~h}$ from birth), milk-fed ( $<2$-mo-old), and growing calves (2-8 mo old) were 25,43 , and $58 \%$, respectively. Forty different STEC serotypes were found among isolates from newborn, milk-fed, and growing calves that shed STEC strains potentially pathogenic for humans. The STEC strains could be acquired early from mothers, enabling the infection of other animal categories and confirming the risk to public health.
\end{abstract}

Key words: Shiga toxin-producing Escherichia coli, calf, Shiga toxin, dairy

\section{Short Communication}

Shiga toxin-producing Escherichia coli (STEC) are considered the main causative agents of hemorrhagic colitis (HC) and hemolytic-uremic syndrome (HUS; Aidar Ugrinovich et al., 2007). In Argentina, HUS is endemic, with 500 cases per year and an incidence of $17 / 100,000$ children less than 5 yr of age (Rivas et al., 2010). Feces of cattle and direct contact with dairy cattle and the dairy farm environment (Oliver et al., 2005), consumption of undercooked meat, nonpasteurized dairy products and vegetables, and water contaminated with feces are some of the possible routes for STEC human exposure (Hussein and Sakuma, 2005).

In several countries, including Argentina, most outbreaks of $\mathrm{HC}$ and HUS have been attributed to the STEC O157:H7 serotype (Rivas et al., 2006) but

Received November 11, 2011.

Accepted May 22, 2012.

${ }^{1}$ Corresponding author: dfer_inm@vet.unicen.edu.ar infections with some non-O157 STEC serotypes are frequently associated with $\mathrm{HC}$ and HUS, mainly in Europe and Latin America (Blanco et al., 2004; Bettelheim, 2007).

Shiga toxin-producing Escherichia coli produce 2 potent toxins called Shiga toxins 1 and 2 (Stx1 and Stx2) encoded by stx1 and stx2 genes (Paton and Paton, 1998). In addition to toxin production, another virulence factor expressed by STEC is intimin (encoded by the chromosomal gene eae), which is responsible for the intimate attachment of STEC to the intestinal epithelial cells, causing attaching and effacing lesions. Other virulence factors of STEC are an enterohemolysin (encoded by the $\boldsymbol{e h} \boldsymbol{x} \boldsymbol{A}$ gene) and the autoagglutinating adhesin (Saa) encoded by the saa gene, which was found in the eae-negative STEC (Paton et al., 2001).

Cattle are the main reservoir of STEC but they are not usually associated with disease. In previous studies, we had demonstrated the role of Argentine cattle as main reservoir of non-O157:H7 serotypes and many of them have been involved in HUS and HC outbreaks worldwide (Fernández et al., 2010). Young calves have been considered the category with the highest prevalence of STEC, although Cobbold and Desmarchelier (2002) found higher prevalence in heifers. However, no studies are available on STEC prevalence in newborn calves. Differences in fecal excretion of STEC by cattle could be due to factors such as age, diet, climate conditions, and animal management, or herd factors such as stocking density, waste management, and housing systems (Vicente et al., 2005). The hypothesis of this work is that a very quick and early colonization of STEC strains potentially pathogenic for humans exist in young calves, allowing the detection of high prevalence in other calf categories.

Between April 2006 and February 2007, newborn $(<24 \mathrm{~h}$ from birth), milk-fed ( $<2$-mo-old), and growing calves (2-8 mo old) from 5 dairy farms in the Pampeana Region of Argentina were sampled by rectal swab. Dairy farms were geographically separated and were named A, B, C, D, and E. Farms had herds in which no outside breeding stock cattle were introduced (closed herds). 
Newborn calves remained with their mothers for $24 \mathrm{~h}$ after birth. Milk-fed calves were fed milk (farms A, B, and E) or milk replacer (farms $\mathrm{C}$ and D) until 2 mo of age. Growing calves (2 to 8 mo of age) were housed in pens and blocked by age, size, and weight and fed a balanced feed according to the nutritional requirements of the NRC (NRC, 2001). All animals in this study were sanitary, fit, healthy, and without treatment with antibiotics or other drugs.

Sample size $(25 \%)$ for each category of calves was determined taking into account an occurrence less than $10 \%$ and a confidence level of $95 \%$. Fecal samples (808) were distributed into 378 samples from newborn calves, 252 samples from milk-fed calves, and 178 samples from growing calves. Newborn and growing calves were sampled by convenience (nonrandom method) during the spring calving season, and milk-fed calves were randomly sampled.

Rectal swabs were immediately transported to the laboratory and plated to obtain confluent growth according to the protocol described by Fernández et al. (2010). Briefly, an aliquot of confluent growth, previously cultured on MacConkey agar plates, was inoculated into $30 \mathrm{~mL}$ of Luria Bertani broth, incubated in an orbital shaking incubator at $37^{\circ} \mathrm{C}$ for $4 \mathrm{~h}$, and processed for DNA extraction (Padola et al., 2004). The stx genes were screened by multiplex PCR (Fernández et al., 2009) and were used as the indicator for STEC. One milliliter from each culture was frozen at $-70^{\circ} \mathrm{C}$ with the addition of $20 \%$ glycerol for isolation of individual stx-positive colonies.

From each stx-positive sample, about 10 to 200 colonies were analyzed by PCR to detect stx 1 and stx2 for isolation of STEC non-O157. For isolation of STEC O157:H7, each stx-positive sample was tested for the presence of $e a e-\gamma 1$ and then subjected to immunomagnetic separation with polystyrene magnetic beads coated with antibodies against the O157 antigen (Dynal Biotech ASA, Oslo, Norway) following the manufacturer's instructions. Then, the concentrated samples were inoculated on sorbitol MacConkey plates. All negative colonies for sorbitol fermentation were confirmed as E. coli O157 with an agglutination test (Oxoid Ltd., Basingstoke, UK; Padola et al., 2004).

Each STEC isolate was also tested for the presence of stx1, stx2, eae, saa, and ehxA by multiplex PCR according to experimental conditions for stx1, stx2, eae, eae- $\gamma$, saa, and $e h x A$ amplification described by Fernández et al. (2010). The $\mathrm{O}$ and $\mathrm{H}$ antigens were determined by a microagglutination technique in plates and by a tube agglutination technique, respectively, with an antisera kit (O1-O186) and $56 \mathrm{H}$ antisera produced by Labora-
Table 1. Shiga toxin-producing Escherichia coli (STEC)-positive calves in 5 dairy farms

\begin{tabular}{lccr}
\hline & \multicolumn{3}{c}{ No. of STEC-positive animals $(\%)$} \\
\cline { 2 - 4 } Farm & $\begin{array}{c}\text { Newborn } \\
(\mathrm{n}=378)\end{array}$ & $\begin{array}{c}\text { Milk-fed } \\
(\mathrm{n}=252)\end{array}$ & $\begin{array}{r}\text { Growing } \\
(\mathrm{n}=178)\end{array}$ \\
\hline $\mathrm{A}$ & $22(37)$ & $28(56)$ & $14(56)$ \\
$\mathrm{B}$ & $16(30)$ & $20(54)$ & $25(75)$ \\
$\mathrm{C}$ & $22(22)$ & $13(24)$ & $22(49)$ \\
$\mathrm{D}$ & $21(20)$ & $17(31)$ & $15(56)$ \\
E & $12(20)$ & $30(54)$ & $27(53)$ \\
Total & $93(25)$ & $108(43)$ & $103(58)$ \\
\hline
\end{tabular}

${ }^{1}$ Calves $<24$ h old.

${ }^{2}$ Calves $<2$ mo old.

${ }^{3}$ Calves 2 to 8 mo old.

torio de Referencia de E. coli (LREC, Lugo, Spain), as described by Blanco et al. (1996).

From 808 samples, $38 \%$ were STEC positive. Differences in STEC prevalence were detected: 25, 43, and $58 \%$ in newborn, milk-fed, and growing calves, respectively (Table 1). These differences could be explained by certain factors and management practices, such as contact between animals, feeding, handling of feces and sewage, and the presence of other domestic animals and insects that could influence the excretion of STEC (Wilson et al., 1993). The present study is the first, to our knowledge, that describes the presence of STEC in newborn calves less than $24 \mathrm{~h}$ old, suggesting that they are exposed to this bacterium quickly after birth and play an important role in vertical transmission of STEC.

Calves fed milk replacer (farms C and D) had lower STEC prevalence than calves fed colostrum or milk (farms A, B, and E; Table 1), suggesting that fecal contamination of milk may occur during milking (Doyle, 1991). The high prevalence of STEC in growing calves was observed in all dairy farms, in agreement with Cobbold and Desmarchelier $(2000 ; 42 \%)$ and Moreira et al. (2003; 49\%). Fernández et al. (2009) found a lower STEC prevalence in dairy cows $(37.5 \%)$ from the same farms of this study. The different prevalence among dairy cows, milk-fed, and growing calves agrees with the results obtained by other authors (Cobbold and Desmarchelier, 2000; Vicente et al., 2005). This high prevalence in calves may be due to several factors that allow better colonization of the gastrointestinal tract, such as factors derived from weaning stress, minor features of the immune system, changes in diet and intestinal $\mathrm{pH}$, and anatomical and physiological changes in the gastrointestinal tract, among other factors.

From the 304 stx-positive samples, 148 STEC isolates were obtained: 26 from newborn, 46 from milk-fed, and 76 from growing dairy calves. Multiplex PCR showed 
that $77 \%$ of STEC isolates from newborn calves carried stx2, $25 \%$ carried stx1, $81 \%$ carried ehxA, $65 \%$ carried eae, and $11 \%$ carried saa.

In milk-fed calves, $46 \%$ of STEC isolates carried stx2, $37 \%$ carried stx1, and $17 \%$ carried stx $1+$ stx2. The $e h x A$, eae, and saa genes were detected in 87,72 , and $15 \%$ STEC isolates, respectively, and only $17 \%$ of strains positive for the $e h x A$ gene showed saa.

In growing calves, $81 \%$ of the STEC isolates carried stx2, $8 \%$ carried stx1, and $10 \%$ carried stx $1+$ stx2. The ehxA, eae, and saa genes were detected in 56, 13, and $29 \%$ of the isolates, respectively. A high percentage of STEC strains isolated from newborn and milk-fed calves carried eae, whereas isolates from growing calves had a low proportion of eae, similar to cows from the same farms (Fernández et al., 2010). In newborns and milk-fed calves, stx2, eae, and $e h x A$ made up the main virulence profile, whereas stx2 and stx2 saa ehxA were the predominant virulence profiles found in growing calves (Table 2).

Previous studies have indicated a relationship between the age of cattle and the stx gene carried, with stx 1 being more predominant in calves and stx2 more common in adult cattle (Cho et al., 2006). However, stx2 was the predominant stx type in all categories of calves, according to previous studies in cattle in Argentina (Fernández et al., 2010). These results are important because Stx2 is more cytotoxic than Stx1 and experimental and epidemiological data have demonstrated that Stx2 may be more important in the development of HUS than Stx1 (Fremaux et al., 2006).

Serotypes O157 and non-O157 of STEC isolates are shown in Table 3. Shiga toxin-producing E. coli O157:H7 was detected in 0.8 and $2.9 \%$ of milk-fed calves and

Table 2. Virulence profile in newborn, milk-fed, and growing calves

\begin{tabular}{lccc}
\hline & \multicolumn{3}{c}{ No. of strains (\%) } \\
\cline { 2 - 4 } Virulence profile $^{1}$ & $3(11)$ & $5(11)$ & $33(43)$ \\
\hline stx2 $^{2}$ Newborn & & Milk-fed $^{3}$ & Growing $^{4}$ \\
stx2, saa, ehxA & $2(8)$ & $6(13)$ & $14(18)$ \\
stx2, eae, ehxA & $15(58)$ & $10(35)$ & $6(8)$ \\
stx1, eae, ehxA & $3(11)$ & $17(37)$ & $4(5)$ \\
stx1, ehxA & $2(8)$ & - & $2(3)$ \\
stx2, ehxA & - & - & $9(12)$ \\
stx1, saa, ehxA & $1(4)$ & - & - \\
stx1, stx2 & - & $1(2)$ & - \\
stx1, stx2, saa, ehxA & - & $3(6)$ & $8(10)$ \\
stx1, stx2, eae, ehxA & - & $4(9)$ & - \\
Total & 26 & 55 & 76
\end{tabular}

${ }^{1}$ Virulence profiles included Shiga toxin 1 (stx1), Shiga toxin 2 (stx2), intimin (eae), enterohemolysin $(e h x A)$, and autoagglutinating adhesin Saa $(s a a)$ genes.

${ }^{2}$ Calves $<24 \mathrm{~h}$ old.

${ }^{3}$ Calves $<2$ mo old.

${ }^{4}$ Calves 2 to 8 mo old.
Table 3. Shiga toxin-producing Escherichia coli serotypes isolated from dairy calves

\begin{tabular}{lll}
\hline & \multicolumn{2}{c}{ Source (calves) } \\
\hline Newborn $^{1}$ & Milk-fed $^{2}$ & Growing $^{3}$ \\
\hline O8:H25 & O5:H- & O2:H25 \\
O11:H21 & O8:H16 & O8:H19 \\
O15:H27 & O15:H- & O26:H11 \\
O26:H11 & O26:H11, H44 & O27:H21 \\
O91:H21 & O55:H- & O64:H- \\
O101:H? ${ }^{4}$ & O103:H8, H21 & O91:H21, H28 \\
O103:H-- ${ }^{5}$ H2, H21 & O111:H-- & O103:H- \\
O111:H- & O113:H2, H21 & O111:H- \\
O145:H- & O141:H42 & O113:H2, H21 \\
O171:H25 & O145:H-- & O153:H25 \\
ONT $: H 10, H 21$ & O153:H25 & O157:H7 \\
& O157:H7 & O163:H19 \\
& O165:H42 & O171:H?, H2 \\
& O172:H- & O172:H- \\
& & O174:H21 \\
& & O178:H- H19, H25 \\
& & ONT:H8 \\
\hline
\end{tabular}

\footnotetext{
${ }^{1}$ Calves $<24$ h old.

${ }^{2}$ Calves $<2$ mo old.

${ }^{3}$ Calves 2 to 8 mo old.

${ }^{4} \mathrm{H}$ ? = an untypeable $\mathrm{H}$ antigen.

${ }^{5} \mathrm{H}-=$ a nonmotile $E$. coli isolated.

${ }^{6} \mathrm{ONT}=$ a nontypeable $\mathrm{O}$ antigen
}

growing calves, respectively, and all carried stx2, eae, and $e h x A$. Shiga toxin-producing E. coli $\mathrm{O} 157: \mathrm{H} 7$ is a serotype detected with a low prevalence in cattle from Argentina, but it is the predominant serotype isolated in human patients in this country (Rivas et al., 2010). This could be due to the use of the selective methods to detect STEC O157 in routine clinical diagnosis. In our study, non-O157 serotypes were isolated in all categories of calves and many of them have been previously isolated from human patients with HUS, diarrhea, or HC in Argentina and other countries (Bettelheim, 2007; Rivas et al., 2010).

The occurrence of O91:H21, O113:H21, O178:H19, and ONT:H21 serotypes were previously reported in dairy cows in the same farms from Argentina (Fernández et al., 2010), indicating the possible transmission of strains among cattle. In newborn and milk-fed calves, STEC O145:H- was also detected, which was first isolated in Argentina in feedlot cattle by Padola et al. (2002) and has previously been involved in outbreaks of HUS in Japan (Kudoh et al., 1994). Currently, this serotype is the second, after O157:H7, most frequently isolated in cases of HUS in Argentina.

Most STEC serotypes isolated in this work carried genes linked to severe forms of human disease, and have been isolated previously in beef cattle, food, and humans (Padola et al., 2004; Rivas et al., 2010). Newborn calves are able to show STEC strains potentially patho- 
genic for humans from the first day of life, allowing the infection of other animal categories, suggesting a vertical transmission and confirming the risk to public health.

\section{ACKNOWLEDGMENTS}

The authors thank María R. Ortiz (Inmunoquímica y Biotecnología, Facultad Ciencias Veterinarias, Universidad Nacional del Centro de la Provincia de Buenos Aires) for her technical assistance. This work was supported by FONCYT PICT 1728/OC-AR Proy 38059, PICT 2010 PROY 1655, CIC, and SECYT-UNCPBA. N. L. Padola is a member of the Scientific Research Commission Prov. Buenos Aires (CIC); D. Fernández is a holder of a fellowship from CONICET.

\section{REFERENCES}

Aidar-Ugrinovich, L., J. Blanco, M. Blanco, J. E. Blanco, L. Leomil, G. Dahbi, A. Mora, D. L. Onuma, W. D. Silveira, and A. F. Pestana de Castro. 2007. Serotypes, virulence genes, and intimin types of Shiga toxin-producing Escherichia coli (STEC) and enteropathogenic E. coli (EPEC) isolated from calves in São Paulo, Brazil. Int. J. Food Microbiol. 115:297-306.

Bettelheim, K. A. 2007. The non-O157 Shiga-toxigenic (verocytotoxigenic) Escherichia coli; under-rated pathogens. Crit. Rev. Microbiol. 33:67-87.

Blanco, J. E., M. Blanco, J. Blanco, A. Mora, L. Balaguer, M. Mouriño, A. Juárez, and W. H. Jansen. 1996. O serogroups, biotypes and eae genes in Escherichia coli isolates from diarrheic and healthy rabbits. J. Clin. Microbiol. 34:3101-3107.

Blanco, M., N. L. Padola, A. Krüger, M. E. Sanz, J. E. Blanco, E. A. González, G. Dahbi, A. Mora, M. I. Bernárdez, A. I. Etcheverria, G. H. Arroyo, P. Lucchesi, A. E. Parma, and J. Blanco. 2004. Virulence genes and intimin types of Shiga-toxin-producing Escherichia coli isolated from cattle and beef products in Argentina. Int. Microbiol. 7:269-276.

Cho, S., F. Diez-Gonzales, C. P. Fossler, S. J. Wells, C. W. Hedberg, J. B. Kaneene, P. L. Ruegg, L. D. Warnick, and J. B. Bender. 2006. Prevalence of Shiga toxin-encoding bacteria and Shiga toxinproducing Escherichia coli isolates from dairy farms and county fairs. Vet. Microbiol. 118:289-298.

Cobbold, R., and P. Desmarchelier. 2000. A longitudinal study of Shiga-toxigenic Escherichia coli (STEC) prevalence in three Australian dairy herds. Vet. Microbiol. 71:125-137.

Cobbold, R., and P. Desmarchelier. 2002. Horizontal transmission of Shiga toxin-producing Escherichia coli within groups of dairy calves. Appl. Environ. Microbiol. 68:4148-4152.

Doyle, M. P. 1991. Escherichia coli O157:H7 and its significance in foods. Int. J. Food Microbiol. 12:289-301.

Fernández, D., K. Irino, M. E. Sanz, N. L. Padola, and A. E. Parma. 2010. Characterization of Shiga toxin-producing Escherichia coli isolated from dairy cows in Argentina. Lett. Appl. Microbiol. 51:377-382.

Fernández, D., E. M. Rodríguez, G. H. Arroyo, N. L. Padola, and A. E. Parma. 2009. Seasonal variation of Shiga toxin-encoding genes $(s t x)$ and detection of E. coli $\mathrm{O} 157$ in dairy cattle from Argentina. J. Appl. Microbiol. 106:1260-1267.

Fremaux, B., S. Raynaud, L. Beutin, and C. Vernozy Rozand. 2006. Dissemination and persistence of Shiga toxin-producing Escherichia coli (STEC) strains on French dairy farms. Vet. Microbiol. 117:180-191.

Hussein, H. S., and T. Sakuma. 2005. Prevalence of Shiga toxin-producing Escherichia coli in dairy cattle and their products. J. Dairy Sci. 88:450-465.

Kudoh, Y., A. Kai, H. Obata, J. Kusunoki, C. Monma, M. Shingaki, Y. Yanagawa, S. Yamada, S. Matsushita, T. Itoh, and T. Ohta. 1994. Epidemiological surveys on verocytotoxin-producing Escherichia coli infections in Japan. Pages 53-56 in Recent advances in verocytotoxin-producing Escherichia coli infections (Excerpt from Medical International Congress Series 1072). M. A. Karmali and A. G. Goglio, ed. Elsevier Science, Amsterdam, the Netherlands.

Moreira, C. N., M. A. Pereira, C. S. Brod, D. P. Rodríguez, J. B. Carvalhal, and J. A. G. Aleixo. 2003. Shiga toxin-producing Escherichia coli (STEC) isolated from healthy dairy cattle in Southern Brazil. Vet. Microbiol. 93:179-183.

NRC. 2001. Nutrient Requirements of Dairy Cattle. 7th rev. ed. National Academy Press, Washington, DC.

Oliver, S. P., B. M. Jayarao, and R. A. Almeida. 2005. Foodborne pathogens in milk and the dairy farm environment: Food safety and public health implications. Foodborne Pathog. Dis. 2:115129

Padola, N. L., M. E. Sanz, J. E. Blanco, M. Blanco, J. Blanco, A. I. Etcheverria, G. H. Arroyo, M. A. Usera, and A. E. Parma. 2004. Serotypes and virulence genes of Shigatoxigenic Escherichia coli (STEC) isolates from a feedlot in Argentina. Vet. Microbiol. 100:3-9.

Padola, N. L., M. E. Sanz, P. M. Lucchesi, J. E. Blanco, M. Blanco, J. Blanco, A. I. Etcheverría, G. H. Arroyo, and A. E. Parma. 2002 First isolation of the enterohaemorrhagic Escherichia coli O145:Hfrom cattle in feedlot in Argentina. BMC Microbiol. 2:6-9.

Paton, A. W., P. Srimanote, M. C. Woodrow, and J. S. Paton. 2001. Characterization of Saa, a novel autoagglutinating adhesin produced by locus of enterocyte effacement-negative Shiga toxigenic Escherichia coli strains that are virulent for humans. Infect. Immun. 69:6999-7009.

Paton, J. C., and A. W. Paton. 1998. Pathogenesis and diagnosis of Shiga toxin-producing Escherichia coli infections. Clin. Microbiol. Rev. 11:450-479.

Rivas, M., E. Miliwebsky, I. Chinen, C. D. Roldán, L. Balbi, B. Garcia, G. Fiorilli, S. Sosa-Estani, J. Kincaid, J. Rangel, and P. M. Griffin. 2006. Characterization and epidemiologic subtyping of Shiga toxin-producing Escherichia coli strains isolated from hemolytic uremic syndrome and diarrhea cases in Argentina. Foodborne Pathog. Dis. 3:88-96.

Rivas, M., N. L. Padola, P. M. Lucchesi, and M. Masana. 2010. Diarrheagenic Escherichia coli in Argentina. Pages 142-161 in Pathogenic Escherichia coli in Latin America. A. G. Torres, ed. Bentham Science Publishers, Oak Park, IL.

Vicente, H. I. G., L. A. do Amaral, and A. de Mello Figueiredo Cerqueira. 2005. Shigatoxigenic Escherichia coli serogroups O157, O111 and O113 in feces, water and milk samples from dairy farms. Braz. J. Microbiol. 36:217-222.

Wilson, J. B., S. A. McEwen, R. C. Clarke, K. E. Leslie, D. WaltnerToews, and C. L. Gyles. 1993. Risk factors for bovine infection with verocytotoxigenic Escherichia coli in Ontario, Canada. Vet. Med. 16:159-170. 